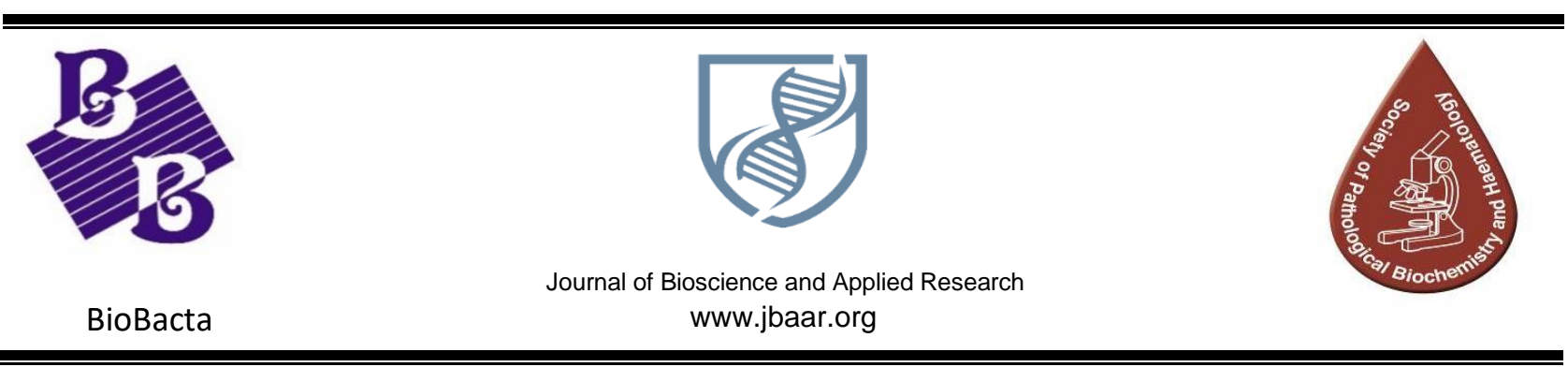

\title{
CDPA-1 Stored Blood Induced Effect on some Haematological Parameters
}

\author{
Nihal Abdalla Bakheit Almokhtar and Nour Mahmoud Abdelateif Ali \\ Department of Hematology, Faculty of Medical Laboratory Sciences, Alneelain University, Khartoum, Sudan. \\ Running head: HAEMATOLOGICAL CHANGES IN CPDA-1 STORED BLOOD \\ DOI: 10.21608/jbaar.2021.195281
}

\begin{abstract}
Background: Most blood collection bags contain $63 \mathrm{~mL}$ CPDA anticoagulant which is sufficient to anticoagulant and ensures the viability of blood cells in $450 \mathrm{~mL} \pm 10 \%$ blood for up to 28-35 days when the blood is stored at $2-8^{\circ} \mathrm{C}$. Prolonged storage of blood leads to alteration in cells hematologically which may lose viability with time. Aim: The study was conducted to determine the effect of storage on CPDA-1 for varying periods on some hematological parameters. Materials and methods: The study was conducted on blood donated by 30 healthy volunteer donors. Effect of storage was analyzed at 1, 7, 14, 21 and 28 days intervals. Hematological parameters were measured using Mindary PS 300 hematology analyzer. Results: There is a highly significant increase in hemoglobin concentration, packed cell volume (P.C.V. \%), MCV, and also a decrease in lymphocyte, granulocyte, and platelet count. The results also showed an insignificant decrease in total white blood cell count. Conclusion: There are degenerative changes observed in blood parameters in samples collected in citrate phosphate dextrose adenine (CPDA-1).
\end{abstract}

Keywords: CPDA-1; Hematological parameters; Storage.

\section{Introduction}

Before the development of the technology involved in blood component preparation, whole blood was the only blood product available. In the 1960s, when plastic replaced glass as the collection medium, separation of whole blood into its components became possible( Kathy D, et al.,2009)

Whole blood is stored in a monitored refrigerator at $1^{\circ} \mathrm{To} 6^{\circ} \mathrm{C}$ for 21 days if collected in CPD or for 35 Days If In CPDA-l. The additive solution cannot be added to whole blood to increase the storage period.

Citrate phosphate dextrose adenine solution was developed in 1968 and shown to permit whole-blood storage for 5 weeks (Shields CE, 1969). Most blood collection bags(adult) contain $63 \mathrm{~mL}$ CPDA anticoagulant which is sufficient to anticoagulate and ensures the viability of blood cells in $450 \mathrm{~mL} \pm 10 \mathrm{~mL}$ blood for up to 28-35 days when the blood is stored at $2-8^{\circ} \mathrm{C}($ Monica $\mathrm{C}, 2003)$.

When blood is stored outside the body, some hematological changes take place resulting in reduced red blood cells survival which is an important drawback when transfused into the circulation of a recipient. Preservation and long-term storage of red blood cells (RBCs) are needed to ensure a readily available, safe blood supply for 
transfusion medicine. Blood collection and storage systems licensed by the Food and Drug Administration allow red cells to be stored up to 42 days, while the median duration of storage of transfused red cell units in the United State is 15 days. Some studies have suggested that the risk of complications after transfusion increases when transfused blood has been stored for long periods (Koch CG, et al., 2008).

When blood is stored in the blood bank, the biochemistry and physical properties of RBCs are altered because of storage conditions. These are referred to as storage lesions. RBC stored for some time at $4^{\circ} \mathrm{C}$ loses viability. Some may undergo spontaneous hemolysis while in storage; others lose the ability to survive in the recipient's circulation following transfusion (Verma M, DahiyaK, et al., 2015). Under normal conditions in the body's circulation, these do not occur as optimum temperature, $\mathrm{pH}$, nutrient concentration, and waste product removal are maintained (Rudmann. SV, 2005).

Storage harms RBC oxygen delivery (Bonaventura J, 2007), and emerging evidence suggests that allogeneic RBC infusion may harm some recipients. Prolonged contact of plasma with RBCs results in an exchange of contents between plasma and red cells which leads to changes in analyte concentrations as well as dilution(VermaM, et al., 2015).

Platelets circulate longer when stored at room temperature and are more activated and able to form clots more effectively when stored at $4^{\circ} \mathrm{C}$ (BruceChwatt LJ, (1972).

White cells lose their phagocytic property within 4-6 hrs of collection and become non-functional after 24 hrs of storage (Thon IN et al., 2008).
Rapid degeneration of leukocytes could lead to immunomodulation related to blood transfusion. Whole blood should be leukodepleted before storage if it must be used beyond one week (Teddy C Adias, et al., 2012).

\section{Materials and Methods \\ Study area and subjects}

This study was conducted in Al Ribat Hospital, located in the city of Khartoum, Sudan. The study was between 4 August and 1 September 2017. Blood (450 ml) was drawn from 30 healthy volunteer donors into Citrate Phosphate Dextrose adenine (CPDA-1) anticoagulant and placed on the quarantine shelf of the blood bank refrigerator.

\section{Blood collection}

Blood was collected from each of the donors in CDPA-1 anticoagulant with care and adequate safety precautions to avoid contamination and infection from blood transmissible pathogens. Protective gloves were worn during collection and syringes were sterile and dry and blood collecting materials were discarded safely to avoid injury from needles and lancets. Blood bags were carefully stored in a quarantine shelf in the blood bank, with temperatures ranging from $2^{\circ}-6^{\circ} \mathrm{c}$ (AdiasTC, et al., 2012).

\section{Procedures:}

Tests were measured using Mindary PS 300 hematology analyzer. The Mindary PS-300 auto Hematology Analyzer (china) was used; PC-300 works on the principle of electrical resistance for counting

\section{Results}

The effect of storage on hematological parameters was evaluated. The blood was kept for 28 days and samples were examined on days $1,7,14,21$, and 28 for hematological parameters the mean value $\left(\mathrm{X}^{-}\right) \pm$ standard error mean (SEM) are performed as shown in table (1) 
Table1: Mean test of significance for all the days.

\begin{tabular}{|c|c|c|c|c|c|c|c|c|}
\hline \multirow[t]{2}{*}{ Parameters } & \multicolumn{5}{|c|}{ Days (Mean $\pm S D$ ) } & \multirow[b]{2}{*}{ Total } & \multirow[t]{2}{*}{$F$} & \multirow{2}{*}{$\begin{array}{l}P \text { - } \\
\text { value }\end{array}$} \\
\hline & Day (1) & Day (7) & Day (14) & Day (21) & Day (28) & & & \\
\hline TWBC * $\left(10^{9}\right)$ & $5.8 \pm 1.7$ & $5.1 \pm 1.6$ & $4.9 \pm 1.4^{*}$ & $4.7 \pm 1.3^{* *}$ & $4.9 \pm 1.5^{*}$ & $5.1 \pm 1.5$ & 2.4 & 0.057 \\
\hline LYMPH (\%) & $37.1 \pm 7.9$ & $45.5 \pm 11.2^{*}$ & $64.0 \pm 19.9^{* *}$ & $75.1 \pm 11.9^{* *}$ & $77.4 \pm 13.5^{* *}$ & $59.8 \pm 20.8$ & 52.5 & 0.000 \\
\hline GRAN (\%) & $54.42 \pm 7.7$ & $42.3 \pm 10.3^{* *}$ & $24.4 \pm 14.9^{* *}$ & $14.4 \pm 5.5^{* *}$ & $12.7 \pm 4.7^{* *}$ & $29.6 \pm 18.7$ & 112.7 & 0.000 \\
\hline HBG (g/dl) & $13.7 \pm 1.2$ & $14.3 \pm 1.4$ & $14.5 \pm 1.4^{*}$ & $13.3 \pm 1.0$ & $14.2 \pm 1.7$ & $14.0 \pm 1.4$ & 4.3 & 0.003 \\
\hline $\mathrm{RBC} *\left(10^{12}\right)$ & $4.7 \pm 0.5$ & $4.8 \pm 0.5$ & $4.9 \pm 0.4^{*}$ & $4.6 \pm 0.4$ & $4.8 \pm 0.6$ & $4.8 \pm 0.5$ & 1.9 & 0.107 \\
\hline HCT (\%) & $41.1 \pm 3.4$ & $43.3 \pm 3.9^{*}$ & $45.3 \pm 3.9^{* *}$ & $42.3 \pm 3.3$ & $46.2 \pm 5.6^{* *}$ & $43.6 \pm 4.4$ & 7.9 & 0.000 \\
\hline MCV (fl) & $87.8 \pm 5.0$ & $89.3 \pm 5.3$ & $91.5 \pm 5.2 *$ & $92.9 \pm 5.8^{* *}$ & $96.4 \pm 6.8^{* *}$ & $91.6 \pm 6.3$ & 10.2 & 0.000 \\
\hline $\mathrm{MCH}(p g)$ & $29.1 \pm 2.3$ & $29.4 \pm 2.1$ & $29.3 \pm 1.9$ & $28.8 \pm 2.3$ & $29.7 \pm 2.2$ & $29.3 \pm 2.2$ & 0.7 & 0.614 \\
\hline $\mathrm{MCHC}(\mathrm{g} / \mathrm{dl})$ & $33.3 \pm 1.4$ & $32.9 \pm 0.9$ & $32.0 \pm 0.7^{* *}$ & $31.3 \pm 1.2^{* *}$ & $30.8 \pm 1.2^{* *}$ & $32.0 \pm 1.5$ & 24.2 & 0.000 \\
\hline $\mathrm{PLT}^{*}\left(10^{9}\right)$ & $221.7 \pm 43.4$ & $156.7 \pm 52.4^{* *}$ & $137.6 \pm 41.6^{* *}$ & $127.8 \pm 32.7^{* *}$ & $128.1 \pm 28.2^{* *}$ & $154.4 \pm 53.4$ & 28.3 & 0.000 \\
\hline PDW & $15.9 \pm 0.3$ & $16.1 \pm 0.5$ & $16.2 \pm 0.4^{*}$ & $16.6 \pm 0.7^{* *}$ & $17.2 \pm .6^{* *}$ & $16.3 \pm 0.7$ & 29.4 & 0.000 \\
\hline РCT (\%) & $0.17 \pm 0.03$ & $0.12 \pm 0.04^{* *}$ & $011 \pm 0.03^{* *}$ & $0.10 \pm 0.03^{* *}$ & $0.11 \pm 0.03^{* *}$ & $0.12 \pm 0.04$ & 18.7 & 0.000 \\
\hline
\end{tabular}

*= Significant at $\mathrm{P}<0.05$

**= Significant at $\mathrm{P}<0.01$

Table1: Mean test of significance for all the days.

\section{Mean values of hematological parameters}

At the end of the study period as shown in table 1 , the mean values of some hematological parameters were as

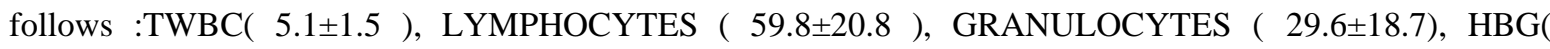

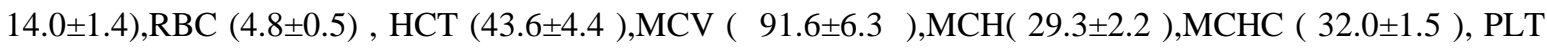
(154.4 \pm 53.4$), \mathrm{PDW}(16.3 \pm 0.7)$ and $\mathrm{PCT}(0.12 \pm 0.04)$. The $\mathrm{P}$ value from day -1 to day 28 were 0.057 for TWBC, 0.000 for lymphocytes, 0.000 for granulocytes, 0.003 for hemoglobin, 0.107 for RBCs, 0.000 for HCT , 0.000 for MCV ,614 for MCH , 0.000 for MCHC, 0.000 for PLT, 0.000 for PDW 0.000 and 0.000 for PCT.

\section{Discussion}

There is substantial evidence from in vitro studies documenting the change that hematological parameters undergo during storage. When changes observed in hematological parameters were categorized based on whether the initial days mean values were maintained when compared with other days, (below the lowest normal value), normal (within the normal range), or high (above the highest normal value), some of the hematological parameters analyzed decreased or increased.

When white blood cells (WBCs) values on day one were compared to day 7 , it was observed that there was a rapid decrease on day seven .this change in white blood cells are most likely due to the changes in sum effects of the loss of individual cell characteristics specifically degeneration that is known to occur as the cell ages. Granulocytes percentage it was observed decreased, Cohle et al., 1981 and Trombridge et al., 1985. There is more increase in neutrophils on day one compared to day seven and more decreased on day seven compared to day one. This is agreed with (Dacieet al., 2001)when blood is a store for a longer period the neutrophils are affected. A progressing increase in lymphocytes on day seven was noticed in this study, there is more 
increased in sample analysis on day seven compared to day one this agrees with (Davey et al., 1986).

Hemoglobin and packed cell volume showed a drastic increase on day 7 compared to day one this is in agreement with the scientist who used turkey on their result experiment their result showed a rapid increase in hemoglobin and packed cell volume.

Platelet decrease on day seven compared to day one. This agrees with the work done by Cohle et al., (1981).

\section{Conclusion}

Blood stored for different periods of storage was found to affect hemoglobin and (P.C.V. \%), they increased slightly, while no significant increase in W.B.C. count and a significant decrease in platelet count.

\section{References}

Adias TC, Moore-Igwe B, Jeremiah ZA (2012)

Storage Related Haematological and Biochemical Changes of CDPA-1 Whole Blood in a ResourceLimited Setting. J Blood Disorder Transfus 3:124. Doi:10.4172/2155-9864.1000124.

Bhargava P, Gupta R, Khare V (2016) CDPA-1 Stored Blood Induced Effect on Hematological and Biochemical Parameter up to 28 Days. Rec. Path. Lab. Med;2 (3\&4).

Bonaventura J (2007) clinical implications of the loss of vasoactive nitric oxide during red blood cell storage. ProcNatlAcadSci U S A 104:19165-19166.

Bruce Chwatt LJ (1972) Blood transfusion and tropical disease. Tropical Disease Bulletin 69:825862.

Cohle, S.D., Abdus S. and Mmakkaowis D.E.(1981); Effects of storage of blood on the stability of hematologic parameters. American journal of clinical pathology.76:67-69.
Dacie, J.V.and Lewis S.M (2001); Differential leucocytes count blood cells, De Grouchy's Clinical hematology $6^{\text {th }}$ Edition. Pp. 4-8.

Kathy D, Blaney, Paula R (2009). Basic and Applied Concepts of Immunohematology.

Koch CG, Li L, SesslerDI,FigueroaP,HoeltgeGA,Hoeltge GA, Mihaljevic T, Blackstone EH.(2008). Duration of red-cell storage and complications after cardiac surgery. N Engl J Med 358: 1229-39.

MonicaC (2000).District Laboratory Practice in Tropical countries, Part 2. Great Britain: Cambridge University Press 348-61.

Monica C (2003). District Laboratory Practice in Tropical Countries, Part 2. Great Britain: Cambridge University Press 348-61.

Rudmann SV (2005). Blood component preservation and storage. Textbook of Blood Banking and Transfusion Medicine. 2ndedn. Elsevier Health Sciences269.

Shields CE (1969). Effect of adenine on stored erythrocytes evaluated by autologous and homologous transfusions. Transfusion 9: 115-19.

Thon JN, Schubert P, Dufuay M, Lin S, KastJ, SerranoK, Devine DV,(2008) comprehensive proteomic analysis of protein changing during platelet storage requires complementary proteomic approaches. Transfusion 48:425-435.

Trowbridge E.A., Reardon, Hutchinson, D., Pickering(1985); the Routine measurement of platelet volume. A comparison of light scattering and aperture-Impedance technologies Clinphysphysilmeas 6:221-238.

Verma M, Dahiya K, Malik D, Sehgal PK, Devi R, Soni Ab, and VEENA Singh Ghalaut. (2015)Effect of blood storage on complete biochemistry. J Blood DisordTransfus 6:6. http://dx.doi.org/10.4172/21559864.1000329. 